\title{
Microstructure and mechanical properties of cold extruded, cellular TRIP-matrix composite structures under quasi-static and dynamic compression
}

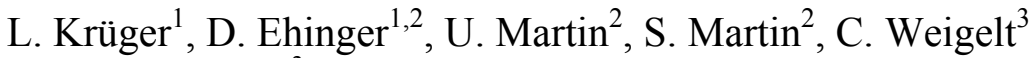 \\ \& C. G. Aneziris ${ }^{3}$ \\ ${ }^{1}$ Institute for Materials Engineering, \\ Technische Universität Bergakademie Freiberg, Germany \\ ${ }^{2}$ Institute for Materials Science, \\ Technische Universität Bergakademie Freiberg, Germany \\ ${ }^{3}$ Institute for Ceramics, Glass and Construction Materials, \\ Technische Universität Bergakademie Freiberg, Germany
}

\begin{abstract}
Novel composites based on austenitic stainless TRIP steel AISI 304 as a matrix with reinforcements of $\mathrm{MgO}$ partially stabilized zirconia (Mg-PSZ) were developed. The presented honeycomb materials were produced by a modified ceramic extrusion technology that is composed of mixing precursor powders with binders, paste preparation and plastic molding, finally debinding and sintering. After processing, sintered products have a global density in the range of 2.7 to $3.0 \mathrm{~g} \mathrm{~cm}^{-3}$ and a wall thickness of $260 \mu \mathrm{m}$. These square-celled honeycomb samples are characterized by optical and scanning electron microscopy before and after quasi-static or dynamic compressive deformation, indicating a noticeable deformation-induced martensite formation. The mechanical properties of samples with up to $10 \% \mathrm{Mg}-\mathrm{PSZ}$ are compared with zirconia-free samples in terms of compression tests at strain rates in the range of $10^{-3}$ to $10^{2} \mathrm{~s}^{-1}$. The honeycomb composite materials exhibit an increased work hardening and also extraordinary high specific energy absorption per unit mass and unit volume, respectively. According to improved property-weight-ratio and excellent crashworthiness, such filigree cellular structures can be beneficial as
\end{abstract}


crash absorbers or stiffened core materials in aerospace, railway or automotive applications.

Keywords: honeycomb, composite, out-of-plane compression, energy absorption.

\section{Introduction}

For several decades famous research institutes and companies have dealt with the development and optimization of low-density cellular or porous composite materials for numerous applications. Polymer and metal honeycomb structures are used as stiffening cores of sandwich panels in train bodies and advanced aerospace components; in particular, metal ones for energy-absorbing applications. For example, the feet of the Apollo 11 landing module already consisted of crushable aluminum honeycombs acting as shock absorbers [1]. Furthermore, a Korean research group evaluated a composite train carbody composed of a bodyshell made of aluminum honeycomb sandwich structure with woven fabric carbon/epoxy face, inner reinforced frames based on mild steel and an underframe manufactured from stainless steel [2]. The Lightweight Structure's group at the Georgia Institute of Technology developed a powder metallurgical technology that allows the fabrication of thin-walled metal honeycomb structures by using the conventional extrusion method and a thermochemical reduction process converting oxide precursor material to metallic products [3-8]. Under quasi-static compression, in the out-of-plane direction, square-celled LCAs ("Linear Cellular Alloys") made of maraging steel revealed mean collapse strengths from 375 to $551 \mathrm{MPa}$ [7]. The highest specific energy absorption of about $90 \mathrm{MJ} \mathrm{m}^{-3}$ was measured for a honeycomb specimen with an in-plane array of $5 \times 5$ cells at $55 \%$ strain [8].

Within the scope of the Collaborative Research Center 799, Aneziris et al. [9] modified the conventional ceramic extrusion technology to create filigree honeycomb shapes based on $\mathrm{MgO}$ partially stabilized zirconia (Mg-PSZ)reinforced austenitic TRIP-steel Matrix Composites (TMC). Exploiting these structural and material benefits, two-dimensional ordered, cellular composites were produced, demonstrating superior strengths, high rates of strain hardening and specific energy absorption based on both macrostructure and microstructure evolution as a result of compressive deformation, as pointed out by Biermann et al. [10].

In this paper, the deformation behavior of the cellular TRIP-steel and TMC specimens under quasi-static and dynamic compressive loading is characterized with regard to strain hardening, particulate reinforcement, strain-rate sensitivity, column and microstructure behavior.

\section{Experimental procedure}

The preparation of the ductile paste was realized by directly batching and mixing the raw materials including plasticizers and water in a conventional single sigmabaking mixer. In order to obtain different composite conditions accurately defined Mg-PSZ proportions were merged with the metastable austenitic TRIP- 
steel AISI 304 powders, denoted as 0Z, 2.5Z, 5Z and 10Z in Table 1. It must be taken into account that the conditions $5 \mathrm{Z}$ and $10 \mathrm{Z}$ were manufactured from stainless steel powder with an average particle size $d_{50}$ of about $45 \mu \mathrm{m}$, whereas the series $0 \mathrm{Z}$ and $2.5 \mathrm{Z}$ were subjected to a more fine-grained steel powder $\left(\mathrm{d}_{50} \approx\right.$ $27 \mu \mathrm{m})$. The multi-celled channel design was achieved by molding the powder mass through the die of a piston extruder at a pressure from 10 to $11 \mathrm{MPa}$ at room temperature. The results were extrudates with a cross-sectional area of 25.5 x $25.5 \mathrm{~mm}^{2}$ comprising 196 channels (200 cpsi). After shape preparation, cubed semi-finished products were dried in an air circulated dryer for $12 \mathrm{~h}\left(40^{\circ} \mathrm{C}\right.$ for 6 $\mathrm{h}$, humidity $80 \%$, followed by $90^{\circ} \mathrm{C}$ for $6 \mathrm{~h}$, humidity $5 \%$ ). The debinding process was carried out at $350^{\circ} \mathrm{C}$ for $90 \mathrm{~min}$ in air before going on with sintering at $1,350^{\circ} \mathrm{C}$ for $2 \mathrm{~h}$ in an electrical tube furnace and $99.9 \%$ Argon atmosphere.

Compression tests on the sintered samples were carried out using a $500 \mathrm{kN}$ servo hydraulic universal testing machine type MTS 880 and a drop impact tester with a drop weight of about $190 \mathrm{~kg}$, respectively. In regard to the latter, the deformation distances are detected by a linear measurement instrumentation based on a magnetic sensor by Kübler Ltd. and the impact is caught by a pneumatically aired spring-loaded brake system by RINGSPANN Ltd. All test bodies were compressed in out-of-plane direction, i.e. normal to the web

Table 1: Chemical compositions for paste preparation.

\begin{tabular}{|c|c|c|c|c|c|}
\hline \multicolumn{2}{|c|}{ Raw Materials } & \multicolumn{4}{|c|}{ Conditions } \\
\hline Product/ Supplier & Type & $0 Z$ & $2.5 Z$ & $5 Z$ & $10 Z$ \\
\hline & & $\mathrm{wt} \%$ & $w t \%$ & $\mathrm{wt} \%$ & $\mathrm{wt} \%$ \\
\hline $\begin{array}{l}\text { Austenitic TRIP-steel } \\
\text { powder (TLS }\end{array}$ & $\begin{array}{l}\text { AISI } 304 \mathrm{~L}, \\
\mathrm{~d}_{50}=27 \mu \mathrm{m}\end{array}$ & 95.97 & 93.72 & - & - \\
\hline Bitterfeld, Germany) & $\begin{array}{l}\text { AISI } 304 \mathrm{~L}, \\
\mathrm{~d}_{50}=45 \mu \mathrm{m}\end{array}$ & - & - & 91.84 & 88.17 \\
\hline $\begin{array}{l}\mathrm{ZrO}_{2} \text { with } 3.5 \mathrm{wt}^{\circ} \% \\
\mathrm{MgO} \text { (Unitec, Stafford, } \\
\text { U.K.) }\end{array}$ & $\begin{array}{l}\text { PMG3.5, } \\
\mathrm{d}_{50}=2 \mu \mathrm{m}\end{array}$ & - & 1.79 & 3.66 & 7.32 \\
\hline $\begin{array}{l}\text { Plasticizer flour } \\
\text { (Kampffmeyer, } \\
\text { Hamburg, Germany) }\end{array}$ & $\begin{array}{l}\mathrm{HW} \text { FGB, } \\
\mathrm{d}_{50}=55 \mu \mathrm{m}\end{array}$ & 3.27 & 3.19 & 2.60 & 2.58 \\
\hline $\begin{array}{l}\text { Tenside (Denk mit, } \\
\text { Henkel, Düsseldorf, } \\
\text { Germany) }\end{array}$ & & - & 0.38 & 0.40 & 0.43 \\
\hline $\begin{array}{l}\text { Dispersant (Degussa, } \\
\text { Germany) }\end{array}$ & $\begin{array}{l}\text { Castament } \\
\text { FS } 60\end{array}$ & - & 0.15 & 0.15 & 0.15 \\
\hline $\begin{array}{l}\text { Plasticizer methyl } \\
\text { cellulose (Aqualon, } \\
\text { Düsseldorf, Germany) }\end{array}$ & HPMC 874 & 0.76 & 0.77 & 1.35 & 1.35 \\
\hline Water & deionized & 7.67 & 5.45 & 4.8 & 5.0 \\
\hline
\end{tabular}


arrangement (cf. $\mathrm{X}_{3}$-loading direction in Fig. 1). In the case of the servo hydraulic machine displacement rates of 0.016 to $20 \mathrm{~mm} \mathrm{~s}^{-1}$ (i.e. strain rates in the range of $10^{-3}$ to $10^{0} \mathrm{~s}^{-1}$ ) could be generated, whereas the drop impact tester offered impact velocities up to $3.7 \mathrm{~m} / \mathrm{s}$, resulted in a strain rate of $2 \times 10^{2} \mathrm{~s}^{-1}$. The stress-strain measurements under compression enabled to evaluate the effects of macro- and microstructure evolution due to martensite formation and zirconia particulate reinforcement on the deformation and strain hardening behavior. Furthermore, aspects like strain rate sensitivity, strain rate hardening or material softening as well as structural phenomena of the honeycomb materials could be estimated. The specific energy absorption (SEA) was examined by calculating the integral of the force-displacement functions, normalized to mass or volume of each sample [11].

\section{Results and discussion}

\subsection{Characterization of the sintered initial state}

Before starting the experimental setup, material parameters, such as average linear shrinkage, open porosity and relative density, were determined for each composite condition (see Table 2$)$. The relative density $\left(\rho^{*} / \rho_{s}\right)$ of the squarecelled honeycomb structure can be defined as a ratio of cell wall thickness $t$ to cell dimension $l$ (as denoted in Fig. 1) based on the empirical approach of Gibson and Ashby [1], adjusted by the term of micro-porosity $P_{m}$ in the cell walls:

$$
\frac{\rho^{*}}{\rho_{s}} \approx\left(1-P_{m}\right)\left[2\left(\frac{t}{l}\right)-\left(\frac{t}{l}\right)^{2}\right]
$$



Figure 1: $\quad 3 \mathrm{D}$ model of the square-celled column defined by cell dimensions and loading directions ( $\mathrm{X}_{3}$ indicates the out-of-plane stress axis). 
Table 2: $\quad$ Material properties of sintered specimens.

\begin{tabular}{|c|c|c|c|}
\hline \multirow{2}{*}{$\begin{array}{c}\text { Fraction of } \\
\text { Mg-PSZ [vol\%] }\end{array}$} & Shrinkage [\%] & Open Porosity [\%] & Relative Density [-] \\
\cline { 2 - 4 } & \multicolumn{3}{|c|}{ after sintering at $1350^{\circ} \mathrm{C} / 2 \mathrm{~h}$} \\
\hline 0 & 10.1 & 10.3 & 0.38 \\
\hline 2.5 & 11.8 & 7.2 & 0.39 \\
\hline 5 & 13.8 & 8.1 & 0.36 \\
\hline 10 & 14.6 & 7.4 & 0.35 \\
\hline
\end{tabular}

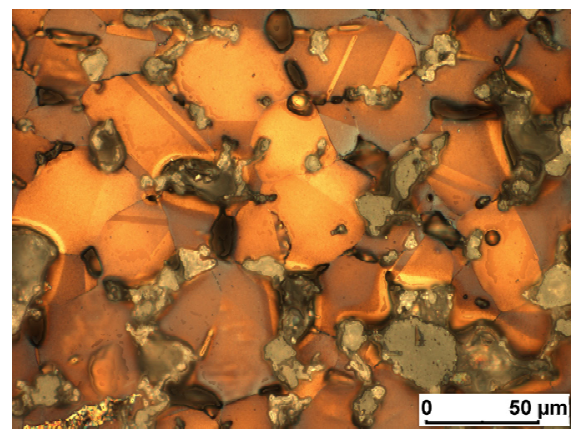

Figure 2: $\quad$ Microstructure inside a cell node of sintered initial state with 10 vol\% Mg-PSZ after Beraha II color etching.

Bocchini [12] has already shown that the micro-porosity can dramatically affect the mechanical characteristics of sintered materials.

The channel elements exhibited wall thicknesses from 250 to $280 \mu \mathrm{m}$ and cell lengths between 980 and $1,100 \mu \mathrm{m}$.

The microstructure evolution from initial to deformed state was documented via scanning electron microscopy and optical microscopy, supported by a Beraha II color etching, respectively. After etching, the as-received state of the composite materials exhibits brown-colored austenitic steel grains, whose triple points are settled by randomly distributed zirconia particles (cf. Fig. 2). The relatively low sintering temperature of $1,350^{\circ} \mathrm{C}$ prohibited the zirconia particles to coalesce to a close-packed assembly, thus some polyhedral pores still remained.

\subsection{Stress-strain behavior at quasi-static and dynamic compressive loading}

The different material conditions were compared in terms of their true stress vs. plastic strain behavior under quasi-static compression at a strain rate of $10^{-3} \mathrm{~s}^{-1}$. The true stress-strain curves of these high-density honeycomb structures exhibit no initial collapse or peak stress, typically observed at thin-walled hexagonal honeycombs [13-14] or square honeycombs [7-8] made by aluminum sheets in terms of a corrugation/stacking process and extruded maraging steel based on the DRM (Direct Reduction Method) LCA technology, respectively. After 


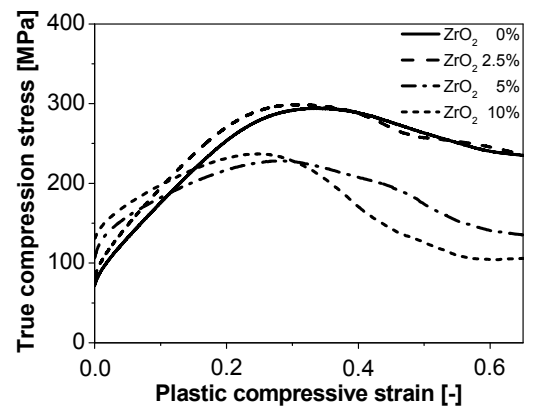

(a)

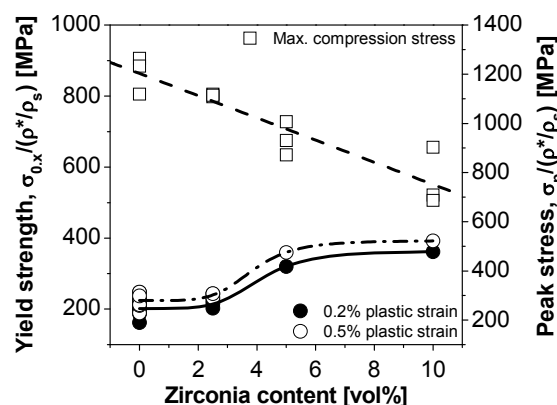

(b)

Figure 3: (a) True compression stress vs. plastic compressive strain and

(b) peak stress and offset yield strength related to different zirconia fractions $\left(\dot{\varepsilon}=10^{-3} s^{-1}\right)$.

exceeding the offset yield strength, the present specimens show a stress increase due to strain hardening of the cell wall material, followed by a maximum compression stress and finally a strength decrease, as shown in Fig. $3 \mathrm{a}$.

Studies on cold isostatically pressed compact samples [10] have already proven the compressive stress at yield rises with increasing volume content of zirconia. In Fig. $3 b$ both the offset yield strengths at $0.2 \%$ and $0.5 \%$ engineering strain and the peak stresses are plotted as functions of zirconia content. In order to include the different material parameters of each composite condition the stress values were normalized to the relative density, listed in Table 2. As expected, the yield stress value of specimen with $10 \mathrm{vol} \%$ zirconia is nearly about 50\% higher than the pure TRIP-steel specimen. The materials with a MgPSZ content of 0 and $2.5 \mathrm{vol} \%$ reveal similar strain hardening behavior, considering that the relatively small ceramic reinforcement results in higher compression stress values (see Fig. 3a). The higher strength level of the conditions $5 \mathrm{Z}$ and 10Z, ascribed by the higher yield points, extends just up to 10 and $13 \%$ compressive strain due to the significantly lower strain hardening compared to $0 \mathrm{Z}$ and $2.5 \mathrm{Z}$. Regarding these two conditions, lower external loads were needed to achieve the material collapse or damage followed by an intense decrease in compression stresses at higher deformation degrees. The measured drop in strength can be explained by the rearrangement of zirconia particles in elongated chains, crack formation on material weak points like the ceramic/steel interface regions (visible in Fig. 6) or at residual pores after processing. In the case of the present honeycomb prototypes, mean engineering compression stresses exhibit a nearly monotonic decline with increasing volume content of zirconia, as shown in Fig 3b. Hence, the average normalized peak stress of the specimens with a Mg-PSZ content of $10 \mathrm{vol} \%$ is about $36 \%$ lower than the unreinforced TRIP-steel samples.

Under quasi-static compression the specimen with 2.5 vol\% zirconia achieved the highest specific energy absorption valued with approx. $170 \mathrm{MJ} \mathrm{m}^{-3}$ at $50 \%$ engineering strain. At lower deformation degrees, the stronger reinforced 
composite materials $5 \mathrm{Z}$ and $10 \mathrm{Z}$ dissipated more energy than the pure TRIPsteel, due to its higher yield stresses. The values of specific energy absorption are listed in Table 3 with respect to the composite conditions and compressive strains.

In summary, the condition $2.5 \mathrm{Z}$ offered the best results under quasi-static loading. Due to this fact, the material was chosen to investigate the stress-strain behavior at medium and dynamic deformation rates compared to the static.

Influenced by varied strain rate the samples revealed different offset yield stresses, strain hardening and strength maxima, respectively (cf. Fig. 4a). In the strain rate range from $10^{-3}$ to $10^{0} \mathrm{~s}^{-1}$ the true compression stress vs. strain curves show just a slight increase in yield stress. However, under dynamic loading above $10^{2} \mathrm{~s}^{-1}$, the compressive yield strength rises dramatically to a measured value exceeding the quasi-static about $44 \%$ (see Fig. $4 b$ ).

Table 3: $\quad$ Specific energy absorption (SEA) of the honeycomb specimens at $20 \%$ and $50 \%$ engineering strain.

\begin{tabular}{|r|c|c|c|}
\hline Specimen & Strain $[\%]$ & SEA $\left[\mathrm{kJ} \mathrm{kg}^{-1}\right]$ & SEA $\left[\mathrm{MJ} \mathrm{m}^{-3}\right]$ \\
\hline $0 Z$ & 20 & 13.4 & 39.7 \\
\hline $2.5 \mathrm{Z}$ (static) & 20 & 14.3 & 43.1 \\
\hline $2.5 \mathrm{Z}$ (dynamic) & 20 & 16.8 & 50.2 \\
\hline $5 Z$ & 20 & 14.1 & 37.5 \\
\hline $10 Z$ & 20 & 15.0 & 40.4 \\
\hline $0 Z$ & 50 & 55.8 & 165.5 \\
\hline $2.5 Z$ (static) & 50 & 56.3 & 169.9 \\
\hline $2.5 Z$ (dynamic) & 50 & 57.0 & 170.9 \\
\hline $5 Z$ & 50 & 47.3 & 125.7 \\
\hline $10 Z$ & 50 & 43.2 & 116.7 \\
\hline
\end{tabular}

static $=$ strain rate of $10^{-3} \mathrm{~s}^{-1}$, dynamic $=2 \times 10^{2} \mathrm{~s}^{-1}$

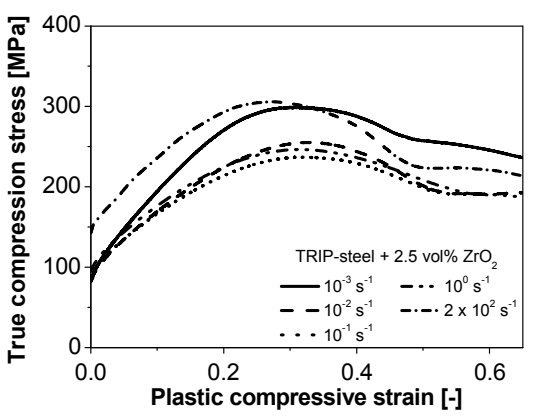

(a)

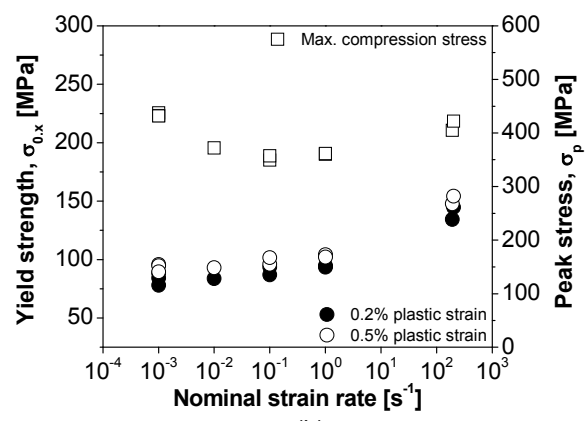

(b)

Figure 4: (a) True compression stress vs. plastic compressive strain and (b) peak stress and offset yield strength as functions of different strain rates for the TMC condition $2.5 \mathrm{Z}$. 
The strain hardening and strain-rate sensitivity are controlled by the intrinsic strain-rate sensitivity due to microstructure kinetics of dislocation/obstacle interactions and by the strain-rate sensitivity of structure evolution, as documented for 304L stainless steel rod and sheet material by Stout and Follansbee [15]. At medium strain rates, a lower strain hardening and lower compression stress values were obtained in contrast to the quasi-static loading. Regarding the wrought material 304L, Stout and Follansbee predicted the strain rate of $10^{-1} \mathrm{~s}^{-1}$ as the limit that indicates the transition between isothermal and adiabatic test conditions. The adiabatic heating during compression decreases the work hardening rate determined by thermal softening and constrained martensite formation. At strain rates of about $10^{2} \mathrm{~s}^{-1}$, dynamic strengthening occurred dominated by the strain-rate sensitivity based on structure evolution.

\subsection{Structural behavior}

The behavior of the multi-celled channel structures is influenced and controlled by material strengthening, zirconia particulate reinforcement and structure softening by material imperfections like pores and cracks in the as-received state as well as by the close-packed cell wall array and high relative density. The effect of height-to-width ratio can be neglected because all samples had similar dimensions.

The investigations on samples of interrupted compression tests have proven that the cell walls can be regarded as rectangular plates stiffened in terms of cruciform elements which deforms in plastic range by local flange buckling (see cell wall oscillations in Fig. 5a) combined with shear crushing mechanisms and particularly by inelastic Euler buckling (see Fig. 5b) [16-17].

At higher deformation degrees, crushing is concentrating in the honeycomb core resulting in the formation of sharp hinges and finally successive failure of selected walls (cf. Fig. 5b).

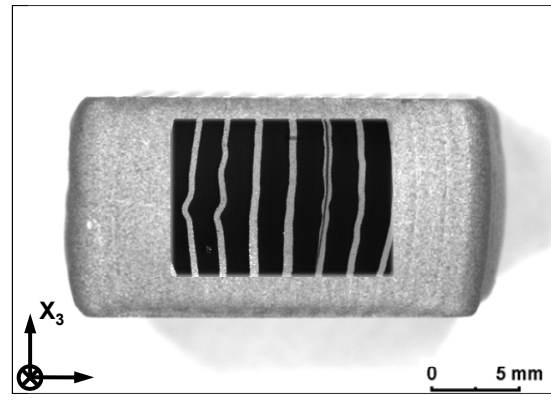

(a)

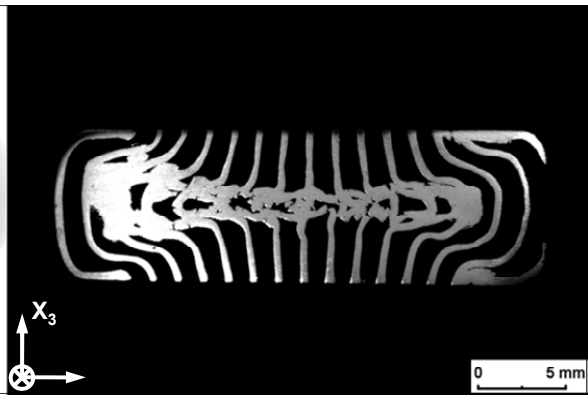

(b)

Figure 5: Collapse patterns of honeycomb specimens: (a) with 0 vol\% Mg-PSZ after 30\% compressive strain and (b) with 2.5 vol\% Mg-PSZ after approx. 60\% strain. 


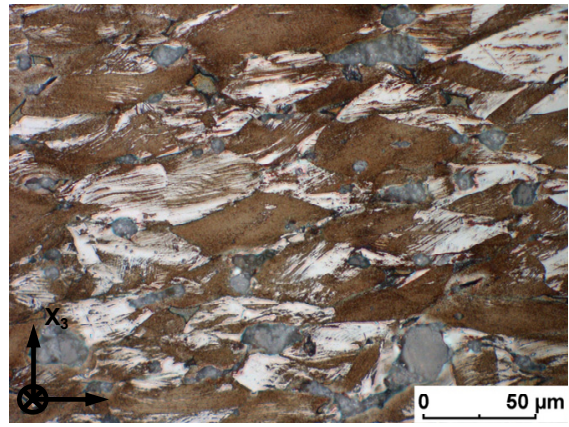

(a)

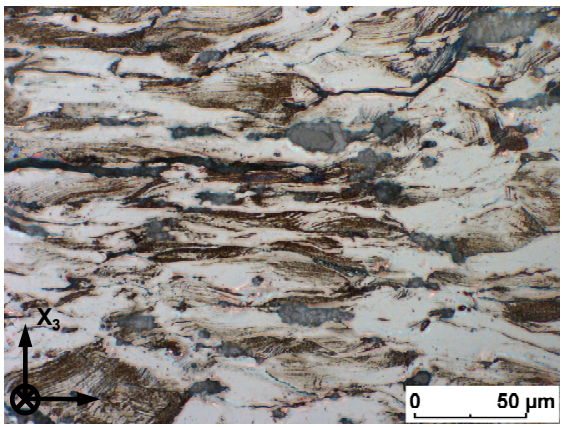

(b)

Figure 6: Microstructure of the composite condition $2.5 \mathrm{Z}$ after $50 \%$ strain at different nominal strain rates, (a) $10^{-3} \mathrm{~s}^{-1}$ and (b) $2 \times 10^{2} \mathrm{~s}^{-1}$

\subsection{Microstructure evolution}

The optical images, presented in Fig. 6 were taken from largely deformed central points of the longitudinal sections of a sample compressed under quasi-static $\left(10^{-3} \mathrm{~s}^{-1}\right)$ and a sample compressed under dynamic impact loading $\left(10^{2} \mathrm{~s}^{-1}\right)$ based on the TRIP-steel Matrix Composite material with $2.5 \mathrm{vol} \% \mathrm{Mg}$-PSZ.

Due to the localized deformation in the cell walls and the agglomeration of zirconia particles inhomogeneous slip band and martensite formation occurred. Furthermore, under dynamic compression the phase transformation was inhibited by internal shear and adiabatic heating. Hence, the ferromagnetic phase contents, obtained by magnetic balance measurements, were $57 \mathrm{vol} \%$ and $21 \mathrm{vol} \%$ under quasi-static and dynamic compression, respectively. The micrograph of the dynamically loaded sample indicates large zones of highly deformed austenite grains (uncolored) containing varied networks of slip-bands and bec martensite, denoted as brown-colored regions in Fig. 6b. However the cross-sectional view of the quasi-statically loaded specimen shows more grains which are completely transformed to compact plates of martensite (cf. large brown-colored sections in Fig. 6a), noticing the phase transformation predominantly started in the immediate vicinity of cracks and zirconia clusters.

\section{Conclusions}

1) The powder metallurgical route of ceramic extrusion has been successfully modified to realize a filigree honeycomb prototype based on pure austenitic stainless TRIP-steel- and TRIP-steel/Mg-PSZ composite materials.

2) The honeycomb structures show high ductility and strength under compressive loads in out-of-plane direction, whereas the mechanical properties are significantly influenced by the added volume content of zirconia to the austenitic steel matrix. The specimen $2.5 \mathrm{Z}$ performed the highest specific energy absorption of approximately $56 \mathrm{~kJ} \mathrm{~kg}^{-1}$ and $170 \mathrm{MJ}$ $\mathrm{m}^{-3}$, respectively. 
3) The strain-rate sensitivity of the honeycomb structure on basis of a MG-PSZ content of $2.5 \mathrm{vol} \%$ is similar to the behavior of the wrought alloy AISI 304L [15] controlled by the kinetics of dislocation/obstacle interactions, changes in thermal conditions and structure evolution. In the interval from quasi-static up to medium strain rates the change in yield stress is denoted by a slightly, but nearly linear increase. At dynamic strain rate above $10^{2} \mathrm{~s}^{-1}$ rapid increase of yield strength to a higher value could be recorded.

\section{Acknowledgement}

The authors would like to thank the German Science Foundation (DFG) for supporting the scientific work in terms of the Collaborative Research Centre TRIP-Matrix Composites (SFB 799).

\section{References}

[1] Gibson, L.J. \& Ashby, M.F., Cellular solids - Structure \& Properties, Cambridge University Press: Cambridge, 1997.

[2] Kim, J.-S., Lee, S.-J. \& Kwang-Bok, S., Manufacturing and structural safety evaluation of a composite train carbody. Composite Structures, 78, pp. 468-476, 2007.

[3] Cochran, J.K., Lee, K.J., McDowell, D.L. \& Sanders, T., Multifunctional metallic honeycombs by thermal chemical processing. Proc. of the $3^{\text {rd }}$ Global Symposium on Materials - Processing and Manufacturing, eds. A. Ghosh, T. Sanders \& D. Claar, TMS: Seattle, Washington, pp. 127-136, 2002.

[4] Dempsey, B.M., Eisele, S. \& McDowell, D.L., Heat sink applications of extruded metal honeycombs. International Journal of Heat and Mass Transfer, 48, pp. 527-535, 2005.

[5] Wang, A.-J., Kumar, R.S. \& McDowell, D.L., Mechanical Behavior of Extruded Prismatic Cellular Metals. Mechanics of Advanced Materials and Structures, 12, pp. 185-200, 2005.

[6] Hurysz, K.M., Oh, R., Cochran, J.K., Sanders, J., T. H. \& Lee, K.J., Modeling powder extrusion pastes for forming light weight multifunctional structures. Proc of the $3^{\text {rd }}$ Global Symposium on Materials - Processing and Manufacturing, eds. A. Ghosh, T. Sanders \& D. Claar, TMS: Seattle, Washington, pp. 167-176, 2002.

[7] Hayes, A.M., Wang, A.-J., Dempsey, B.M. \& McDowell, D.L., Mechanics of linear cellular alloys. Mechanics of Materials, 36, pp. 691-713, 2004.

[8] Hayes, A.M., Compression Behavior of Linear Cellular Steel. Thesis, School of Materials Science and Engineering, Georgia Institute of Technology, Atlanta, GA, 2001.

[9] Aneziris, C.G., Schärfl, W., Biermann, H. \& Martin, U., Energy-Absorbing TRIP-Steel/Mg-PSZ Composite Honeycomb Structures Based on Ceramic Extrusion at Room Temperature. International Journal of Applied Ceramic Technology, 6(6), pp. 727-735, 2009. 
[10] Biermann, H., Martin, U., Aneziris, C.G., Kolbe, A., Müller, A., Schärfl, W. \& Herrmann, M., Microstructure and compression strength of novel TRIP-steel / Mg-PSZ composites. Advanced Engineering Materials, 11(12), pp. 1000-1006, 2009.

[11] Jakob, G.C., Fellers, J.F., Simunovic, S. \& Starbuck, J.M., Energy absorption in polymer composites for automotive crashworthiness. Journal of Composite Materials, 36, pp. 813-850, 2002.

[12] Bocchini, G.F., The Influence of Porosity on the Characteristics of Sintered Materials. International Journal of Powder Metallurgy, 22(3), pp. 185-202, 1986.

[13] Mohr, D. \& Doyoyo, M., Large plastic deformation of metallic honeycomb: orthotropic rate-independent constitutive model. International Journal of Solids and Structures, 41, pp. 4435-4456, 2004.

[14] Hong, S.-T., Pan, J., Tyan, T. \& Prasad, P., Quasi-static crush behavior of aluminum honeycomb specimens under compression dominant combined loads. International Journal of Plasticity, 22, pp. 73-109, 2006.

[15] Stout, M.G. \& Follansbee, P.S., Strain Rate Sensitivity, Strain Hardening, and Yield Behavior of 304L Stainless Steel. Journal of Engineering Materials and Technology, 108, pp. 344-353, 1986.

[16] Shanley, F.R., Inelastic Column Theory. Journal of the Aeronautical Sciences, 14(5), pp. 261-268, 1947.

[17] Hutchinson, J.W., Plastic Buckling. Advances in Applied Mechanics, 14(12), pp. 67-144, 1974. 